tsteadily losing ground. On the last examination of the whest physical signs were found on ausculta'ion at the left apex. leaving no doubt about that side being affected, a fact which the $x$ rays had shown to be the case some cweeks previously.

Harley-street, $W$

\section{Climital a thates:}

\section{MEDICAL, SURGICAL, OBSTETRICAL, AND THERAPEUTICAL.}

\section{THE OPTICAL EFFECT OF REMOVAL OF THE LENS IN MYOPIA.}

By W. AdAMS Frost, F.R.C.S. Eng., OPHTHALMIO SURGEON TO ST. GEORGE'S HOSPITAL, ETC.

IN deciding whether a particular case of myopia is likely to be benefited by removal of the lens the optical effect of the operation is so important a factor that it is a pity that there should be any misconception with regard to it. A great many inaccurate and misleaoing statements have, however, been made by writers on this subject, while many either ignore this branch of it, or treat it by means of mathematical formulæ which are rather alarming to the average reader. Tne only points which are of practical importance van be made clear without any abstruse calculations, especially if we are careful not to confound two different thingsthe effect of the operation on the actual refraction of the eye and its effect on the correcting lens required.

With regard to the refraction if we confine the term to the influence exerted by the refracting surfaces and media of the eye on rays entering it it is evident that if the lens has the same value in all cases and lies in the same position relative to the cornea-and there is no evidence that myopia has any influence on either of these conditions-then the effect on the refraction of removing the lens must be the same in all cases.

When we consider the effect of the operation on the correcting lens required for the myopia we introduce another factor, the length of the eye, or the position of the screen on which it is required to throw images of external objects. It is a well-known fact that in the complete eye every millimetre of difference in length produces about $3 \mathrm{D}$. of myopia or hypermetropia, but when we remove the crystalline lens we alter the character of the eye as an optical instrument and make it a much weaker instrument than it was before. Consequently, changes in its length produce less effect, each millimetre of length now corresponding to only $1.38 \mathrm{D}$. We may indeed compare the complete eye and the aphakic eye to the high and low powers of a microscope. With the high power (corresponding to the complete eye) a fraction of a turn of the ine adjustment will make an appreciable difference, while with the low power (corresponding to the aphakic eye) several turns would be required to produce the same effect. The length of the emmetropic eye is about 23 millimetres, but the emmetropic length of the aphakic eye is about 31 millimetres-the focal length of the cornea. Therefore abnormalities in length are calculated from different standards in the complete and in the aphakic eye, the difference being eight millimetres.

The practical effect of these facts will be rendered clear by a few examples. 1. Myopia $15 \mathrm{D} .-$ The eye is therefore five millimetres too long. After removal of the lens the length would have to be eight millimetres more than the emmetropic eye. It is only five millimetres, therefore the eye is three millimetres too short and for correction it would require +4 D. $(3 \times 1 \cdot 38)$. 2. Myopia 24 D.-The eye is therefore eight millimetres too long, but after removal of its lens the length will be exactly right. 3. Myopia $30 \mathrm{D}$.The eye is therefore 10 millimetres too long. After removal of the lens it will be two millimetres too long $(10-8)$, therefore it will require for correction $2 \cdot 75 \mathrm{D}$. $(2 \times 1 \cdot 38)$. It will be seen that the optical effect of the operation as regards the myopia in the first example is $19 \mathrm{D}$. (the difference between -15 and +4$)$. In the second the effect is $24 \mathrm{D}$., and in the third the effect is $28 \mathrm{D}$. $(30-2)$. In other words, the greater the degree of the myopia the more it is affected by the operation.

It must be borne in mind that I have not used exact figures and consequently the results do not agree with those found in actual practice but they correspond fairly closely.

Cavendish-square.

HEMORRHAGE DURING AN OPERATION FOR CONVERGENT STRABISMUS.

By Mary R. Wilson, M.D. Corneli, U.S.A.

Division of a rectus muscle for the relief of strabismus is rarely associated with, or followed by, any complication. The following case in which rather alarming bleeding was observed is perhaps sufficiently uncommon to be recorded in the pages of THE LANCET. The patient was under the care of Mr. Sydney Stephenson, by whose kindness I am enabled to publish the notes.

A girl, aged 11 years, was admitted to the Ophthalmic School at Hanwell on Feb. 9th, 1899, suffering from sub-acute inflammation of the conjunctiva due to the diplo-bacilli described by Morax. ${ }^{1}$ She also had a convergent strabismus of the left eye measuring nearly $50^{\circ}$. The squinting eye "fixed" fairly well and showed no limitation of outward morement, and the primary and secondary deviations were equal. At this time right vision equalled $\frac{6}{12}$ and No. $4 \mathrm{~J}$. at 12 centimetres, and left vision equalled $\frac{\pi}{6}$ and No. $10 \mathrm{~J}$. at 27 centimetres. When under atropine the eye tended to become straight, yet, curiously enough, correction spectacles (right eye +6 D. sph.; left eye +7 D. sph.) did not influence the size of the strabismus in the least. Corrected vision equalled $\frac{6}{y}$ for each eye. No diplopia could be detected and the fundi were normal. On April 3rd it was decided to operate for the strabismus. The child, it was thought, would bear the operation well if the eye were put under the influence of a solution of bydrochlorate of cocaine (2 per cent.). She proved, however, so exceedingly refractory that division of the internal rectus of the squinting eye was accomplished with difficulty. The moment the operation appeared to be completed, a jet of what seemed to be arterial blood issued from the conjunctival wound, and in the course of a few seconds the eyeball became thrust forward and the lids so greatly thickened by the effusion of blood in their tissues that removal of the speculum was a difficult matter. A pad and roller bandage were firmly applied and the child was put to bed immediately. Two and a half hours later the eye was examined, when the lids were found to be much distended, the upper one being purplish and the lower one of a light-greenish colour. There had been some pain which, it was said, had disappeared. The temperature was normal. On April 4th the lids were swollen so much that they could not be opened, while the swelling had extended to the side of the face. The lids were greatly discoloured, the upper one especially, but there was no pain. The temperature rose to $99^{\circ} \mathrm{F}$., the highest point reached during the continuance of the trouble. The eye was kept firmly bandaged. Two days later (April 6th) the temperature was again normal and there was no pain. The discolouration and swelling of the lids persisted but the latter were slightly opened with little difficulty. The cornea was bright and the child counted fingers. The eyeball was still proptosed, but not markedly, while the swelling had not disappeared from the side of the face. The movements of the eye in the orbit were good. The pad and bandage were re-applied. By the 8th the left eye was better in every way but a new feature presented : ecchymosis had passed through the cellular tissue of the bridge of the nose and extended to the right eye. On the 10th the child was able to open the lids of the left eye a little and although there was much effusion of blood beneath the ocular conjunctiva there was neither pain nor uneasiness. On the 13th the child could open the lids of the left eye. Much ecchymosis existed but the lids could be everted. Ecchymosis was present also on the right side of the nose and the lower lid of the right eye. A fortnight later, on the 26th, a faint discolouration of the skin of the lids, side of the nose, and left cheek still persisted. There was also a bright red ecchymosis in the ocular conjunctiva on the outer side of the globe near the corneal margin and the discolouration had not disappeared from the lower lid. 
The magnitude of the strabismus was much the same as before the operation. Correcting glasses were substituted for the bandage. A month afterwards, on May 29th, there was still a trace of hæmorrhage outside the cornea in the ocular conjunctiva and the lower lid was somewhat discoloured On June 2nd ether was administered and Mr. Stephenson, after dividing the left internal rectus, shortened and advanced the external rectus. Pads and a roller bandage were applied to both eyes and the patient was again put to bed. On June 6th, the position of the eye being excellent, the bandage was discarded, the patient was put upon atropine (two grains to the ounce twice a day), and given a double shade with spectacles for constant wear. The sutures were removed on June 13th and the child was discharged frum the Ophthalmic School shortly after with eyes perfectly straight.

Dorset-square, N.W.

\section{A CASE OF CEREBRO-SPINAL MENINGITIS WITHOUT FEVER OR RETRACTION OF NECK.}

By David A. Belilios, M.R.C.S. ENG., L.R.C.P. Lond.

Is a paper on Cerebro-Spinal Meningitis published in THE LANCET of June 24th Dr. Osler mentioned a case where a diagnosis of that disease had been made but where there had been no fever or rigidity of the muscles of the neck. The fact that no cases had previously been recorded without these two symptoms (which are almost supposed to be pathnognomonic of the disease) being present induces me to publish a somewhat similar case which, however, showed other signs more suggestive of cerebro-spinal meningitis.

The patient, a married woman, 25 years of age, was suddenly taken ill whilst performing some of her usual duties. She complained of severe pains in the head and soon afterwards she vomited. Her health previously had been good. When I first saw the patient, about three-quarters of an hour after the seizure, she was delirious and somewhat cyanosed. The pulse-rate was 80 and the respirations were 17. The heart was normal and the lungs were clear. She answered no questions and did not seem to take notice of anything. Tapping the back of the head seemed to cause her some pain. There was no tenderness of the abdomen. The spleen could not be felt below the costal margin. The temperature was normal, the head was not drawn back, and no paralysis could be made out. She continued in this state till the third day, the mental condition during this time being marked by stages of unconsciousness and delusions. The pupils, which up to that time had been normal and had reacted to light, became irregular and dilated, and they did not contract on stimulation. The retinal vessels were full and there was some blurring of the discs. There was slight internal strabismus. About this time also tonic spasm of both arms came on although the muscles of the neck were normal. The bowels were constipated and she passed her urine beneath her. About the fourth week from the onset a papular rash developed on the face and thorax. The pulse varied, sometimes being full and regular and at other times irregular and small, and occasionally the rate dropped to 60 . The temperature was often subnormal. The patient continued in this condition for 13 weeks, her mental state being unchanged. She then showed signs of improvement, the mind gradually cleared, and she is now convalescent.

Kingswood, Bristol.

Britrsh Hospital, Buenos Ayres.-The annual report of the British Hospital, Buenos Ayres, shows that during 1898 there were 1286 admissions of patients, 75 deaths, and 3573 attendances of out-patients. The principal causes of death were-tuberculosis (17 cases), enteric fever (10 cases), heart disease (seven cases), and pneumonia (six cases). A large number of surgical operations were performed, 468 (with 420 successful results and seren deaths) being tabulated as general surgical operations, and 162 (with 151 successful results and eight deaths) as abdominal operations. No reference is made to the medical staff beyond the statement that the committee have made an arrangement "by which a continuance of Dr. O'Conor's most valuable services is secured to the hospital." A paper by Dr. O"Conor was published in the "Mirror" of THE LANCE? of July 8th.

\section{g a whtirror}

\section{H OSPITAL PRACTICE, BRITISH AND FOREIGN.}

Nulla autem est alia pro certo noscendi via, nisi quamplurimas os morborum et dissectionum historias, tum aliorum tum proprias collectas habere, et inter se comparare.-MonGAGNI De Sed. et Caus. Morb., lib iv. Proomium.

\section{RUGELEY DISTRICT HOSPITAL.}

A CASE OF SEVERE MULTIPLE INJURIES; LAPAROTOMT: DEATH IN THREE MONTHS.

(Under the care of Dr. W. L. HubBard.)

THE cyst containing bile-stained fluid which is described in the accompanying case was in all probability a localised portion of the peritoneal cavity containing bile from a slightly torn bile duct. It is a remarkable fact that in certain cases effusion of bile may occur and give rise to nothing more than a very slight inflammation of the peritoneum. It is probable that in all the cases in which no severe inflammation follows the effusion the pouring out of the bile is due to an injury; but when through overdistension a gall bladder gives way the peritonitis which results is genera'ly severe and probably fatal. The difference between these two results is to be explained by the presence or absence of micro-organisms. Healthy bile is absolutely sterile, but when it is retained bile is sure to contairs microbes.

A married woman, aged 34 years, who had borne 12 children, was taken to the Rugeley District Hospital on Feb. 8th, 1899, having some hours before been knocked down by a cart, the wheels of which bad passed over ber left lower extremity, abdomen, thorax, and skull. She had lain out in the rain for some considerable time and her clothing was completely soaked. On admission the patient was in a state of extreme collapse; she was pulseless, the face was cyanosed, the extremities were cold, and the temperature was subnormal, but she was conscious. Examination showed? signs of fracture through the anterior fossa of the skull, subconjunctival hæmorrhage and bleeding from the mouth and nose existing. A rib on the right side was fracture and the lower extremities were extensively contused but there was no fracture. The patient was four and a half months pregnant. By the application of restoratives she rallied considerably and during the first night aborted. Two days later traumatic pneumonia developed on the right side, but the more acute symptoms subsided in 10 days. On the 17 th it was noted that the abdomen was somewhat distended and the urine, which up to that date had been normal both in quantity and chemically, became very scanty. The patient's skin was also slightly jaundiced. On the 24 th she complained of acute pain in the region of the gallbladder and the abdomen continued to enlarge especially on the left side. By March 5th a distinct tumour was evident which was somewhat circular in shape and dull on percussion, the percussion note not being affected by position. Dyspncea was so marked and the respirations were so shallow that it was deemed advisable to draw off the fluid and 13 pints of a light brownish alkaline liquid which became cloudy and green on exposure were evacuated by means of a fine trocar and cannula. The nitric acid test showed that bile was present in this fluid. 'The tapping gave marked relief, but the fluid again accumulated and on the $17 \mathrm{th} 12$ pints more of a fluid similar in character were drawn off. The stools throughout were normal in appearance and were never pale or claycoloured. The temperature from the time of the accident varied between $975^{\circ}$ and $1015^{\circ} \mathrm{F}$. On the 20th Mr. Chavasse kindly came over from Birmingham and saw the patient. At the consultation it was agreed that an abdominal section should be at once performed. This was accordingly done under chloroform, the abdomen being opened by a four-inch incision at the edge of the left rectus muscle. Several pints of fluid escaped and a Jarge cavity, which was, as far as could be ascertained, quite distinct from the peritoneal cavitr and which occupied the left hypochondriac and umbilical regions, was disclosed; this was carefully sponged 